\title{
Studies on the Thiophene Analogues of Malachite Green. I. Protolytic Equilibria and Reaction Rate Constants of Thiophene Green in Aqueous Solutions
}

\author{
RUNE CIGEN and GÖSTA BENGTSSON \\ Department of Inorganic and Physical Chemistry, Chemical Institute, University of Lund, \\ Lund, Sweden
}

\begin{abstract}
The protolytic equilibria and the rate constants of a Thiophene analogue of Malachite Green (MG), named Thiophene Green (TG), have been investigated spectrophotometrically in aqueous solutions with constant ionic strength $0.5 \mathrm{M}$ at $20.0^{\circ} \mathrm{C}$.

The results of the measurements have been compared with the results of the corresponding measurements of $M G$ and the hydroxy. and methoxy-derivatives of MG. It was found that the hydration reactions of TG proceed more slowly and that the values of the hydration constants $K_{2}$ and $1 / K_{6}$ are lower in TG than in MG. In this respect TG is similar to the ortho- and para-hydroxy and -methoxy derivatives of MG.

The reaction scheme used in previous investigations of MG and of derivatives of MG has been extended for the reactions in strongly acid solutions in order to explain some results of the kinetic measurements of TG.
\end{abstract}

$\mathrm{T}$ he dyestuff Thiophene Green (TG) was first prepared by Levi ${ }^{1}$. Later Mason and Nord ${ }^{2,3}$ have investigated Thiophene Green and some derivatives of it as regards their absorption curves, which were compared with the absorption curve of Malachite Green.

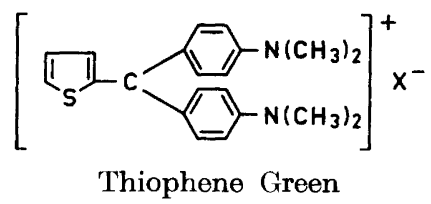

The present investigation is devoted to the protolytic and hydration reactions of TG in aqueous solutions, which have a constant ionic strength of $0.5 \mathrm{M}$.

The same reaction scheme that has been used in earlier studies on derivatives of Malachite Green ${ }^{4-7}$ has been tried on Thiophene Green. It was found Acta Chem. Scand. 16 (1962) No. 8 
that in its reactions TG is similar to Malachite Green. However, the substitution of a phenyl group for a thienyl group has a marked influence on the hydration equilibria and the rate constants. Furthermore, the kinetic measurements in $\mathrm{HCl}+\mathrm{KCl}$-buffers indicate a more complicated reaction scheme than that which was used for Malachite Green. In the discussion part of this paper the differences between Malachite Green and Thiophene Green will be further treated.

In neutral aqueous solutions Thiophene Green is really green in contrast to Malachite Green and many of its derivatives, which are blue or blue-green. If the solution of $\mathrm{TG}$ is made acid, $\mathrm{pH} \approx 0$, it turns red immediately and is then partially decolourized owing to hydration reactions. If the green solution of TG is made alkaline, it is completely decolourized at a rate that is directly proportional to $\left[\mathrm{OH}^{-}\right]$. The above-mentioned reactions can be visualized with the following reaction scheme, which, however, does not consider the complications which arise in strongly acid solutions and which are discussed later in this paper. In the scheme is $\mathrm{R}=2 \mathrm{~N}\left(\mathrm{CH}_{3}\right)_{2}$

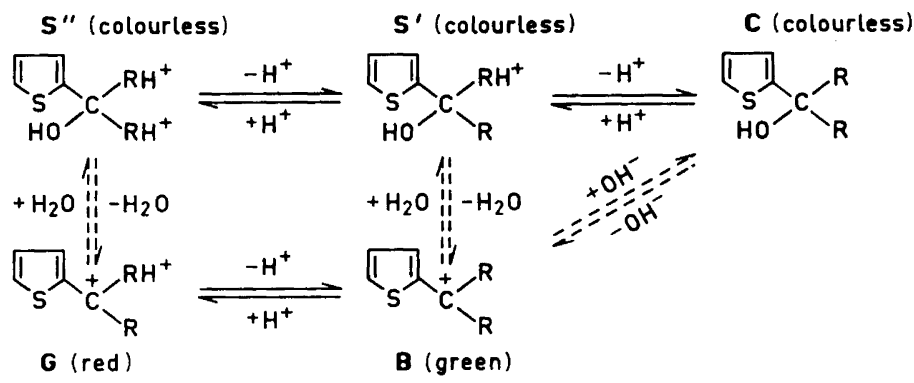

Full drawn arrows indicate that the reactions proceed at an immeasurable rate, i.e., instantaneously, whereas dashed arrows indicate that the reactions take place at a measurable rate.

Definitions of constants and symbols

$$
\begin{aligned}
& K_{1}=\frac{[\mathrm{G}]}{[\mathrm{B}]\left[\mathrm{H}^{+}\right]} ; K_{2}=\frac{\left[\mathrm{S}^{\prime \prime}\right]_{\infty}}{[\mathrm{G}]_{\infty}} ; K_{3}=\frac{\left[\mathrm{S}^{\prime}\right]\left[\mathrm{H}^{+}\right]}{\left[\mathrm{S}^{\prime \prime}\right]} ; K_{4}=\frac{[\mathrm{C}]\left[\mathrm{H}^{+}\right]}{\left[\mathrm{S}^{\prime}\right]} ; \\
& K_{6}=\frac{[\mathrm{B}]_{\infty}}{\left[\mathrm{S}^{\prime}\right]_{\infty}} \\
& \mathrm{h}=\left[\mathrm{H}^{+}\right] ; \text {oh }=\left[\mathrm{OH}^{-}\right] ; K_{\mathrm{w}}=\left[\mathrm{H}^{+}\right]\left[\mathrm{OH}^{-}\right] \text {. } \\
& k_{1}=\text { rate constant for the reaction } \mathrm{G}+\mathrm{H}_{2} \mathrm{O} \rightarrow \mathrm{S}^{\prime \prime} \\
& k_{2}=" \text { " " " } " \mathrm{~S}^{\prime \prime} \rightarrow \mathrm{G}+\mathrm{H}_{2} \mathrm{O} \\
& k_{3}=" \text { " " " " } \quad \mathrm{B}+\mathrm{H}_{2} \mathrm{O} \rightarrow \mathrm{S}^{\prime} \\
& k_{4}=" \text { " " " " } \quad \mathrm{S}^{\prime} \rightarrow \mathrm{B}+\mathrm{H}_{2} \mathrm{O} \\
& k_{5}=" \text { " " " } \quad \mathrm{B}+\mathrm{OH}^{-} \rightarrow \mathrm{C} \\
& k_{6}=" \text { " " " } \quad \text { " } \rightarrow \mathrm{B}+\mathrm{OH}^{-} \\
& k=\text { " " " total reaction } \\
& \varepsilon_{\mathrm{B}}, \varepsilon_{\mathrm{G}}=\text { the molar extinction coefficient of } \mathrm{B} \text { and } \mathrm{G}
\end{aligned}
$$


$e_{\mathrm{o}}, e_{\mathrm{t}}, e_{\infty}=$ the absorbancy per $\mathrm{cm}$ of a solution at the times 0 and $t$ and at equilibrium.

$E_{\mathrm{o}}, E_{\mathrm{t}}, E_{\infty}=$ the total absorbancy.

$e_{\mathrm{B}}, e_{\mathrm{G}}=$ the absorbancy per $\mathrm{cm}$ of a solution containing only $\mathrm{B}$ or $\mathrm{G}$.

$C_{\mathrm{M}} \quad=$ the total concentration of dyestuff.

The constants in the equilibrium scheme can be calculated, if the following quantities are determined for a large number of solutions with varying $\mathrm{pH}$ :

1. The absorbancy, $e_{\mathrm{o}}$, at a moment immediately after the mixing of a dye stock solution with the appropriate buffers. The dye stock solution is (if possible) prepared in such a way that all of the dye is present as the coloured species B.

2. The absorbancy, $e_{\infty}$, when equilibrium is reached.

3. The $\mathrm{pH}$ of the solutions.

4. The total rate constant, $k$, for the reactions that change the intensity of the colour of the solutions either by the hydration of the coloured species (B and $G)$ to colourless species $\left(C, S^{\prime}, S^{\prime \prime}\right)$ or vice versa.

\section{Equations}

The following equations are used for the calculations of the constants in the reaction scheme

$$
\begin{gathered}
e_{\mathrm{o}}=\frac{e_{\mathrm{B}}+\mathrm{h} K_{1} e_{\mathrm{G}}}{1+\mathrm{h} K_{1}} \\
e_{\infty}=\frac{e_{\mathrm{B}}+\mathrm{h} K_{1} e_{\mathrm{G}}}{1+\mathrm{l} / K_{6}+\bar{K}_{4} / \mathrm{h} K_{6}+\mathrm{h} K_{1}\left(1+K_{2}\right)} \\
k=\frac{k_{2} \mathrm{~h}^{2}+k_{4} \mathrm{~h} K_{3}+k_{6} K_{3} K_{4}}{\mathrm{~h}^{2}+\mathrm{h} K_{3}+K_{3} K_{4}}+\frac{k_{1} \mathrm{~h} K_{1}+k_{3}+k_{5} \mathrm{oh}}{1+\mathrm{h} K_{1}}
\end{gathered}
$$

Eqn. (1) is transformed to

$$
\frac{\mathrm{h}}{e_{\mathrm{B}}-e_{\mathrm{o}}}=\frac{\mathrm{h}}{e_{\mathrm{B}}-e_{\mathrm{G}}}+\frac{1}{K_{1}\left(e_{\mathrm{B}}-e_{\mathrm{G}}\right)}
$$

and $K_{1}$ is determined by a graphical method.

In acid solutions, $\mathrm{pH} \leq 2$, we can approximate eqn. (2) and write

$$
K_{2}=\frac{e_{\mathrm{G}}}{e_{\infty}}+\frac{e_{\mathrm{B}}-e_{\infty}\left(1+\mathrm{h} K_{1}+1 / K_{6}\right)}{\mathrm{h} K_{1} e_{\infty}}
$$

In weakly alkaline solutions eqn. (2) is approximated and transformed to

$$
\frac{\mathrm{h}}{e_{\infty}}=\mathrm{h} \frac{1+K_{6}}{K_{6} e_{\mathrm{B}}}+\frac{K_{4}}{K_{6} e_{\mathrm{B}}}
$$

According to eqn. (6), a straight line can be obtained, from which $\left(1+K_{6}\right) / K_{4}$ is obtained. 


\section{EXPERIMENTAL}

Chemicals and solutions. Thiophene Green. The leuco base was prepared according to Levi ${ }^{1}$ by the condensation of $\mathrm{N}, \mathrm{N}$-dimethylaniline with 2-thiophenealdehyde. We used concentrated hydrochloric acid as a condensing agent, however, instead of zinc chloride. The leuco base was recrystallized from ethanol and obtained as light brown needles (m.p. 92-94 ${ }^{\circ}$. The oxidation to dyestuff was performed with lead dioxide, added to a cooled solution of the leuco base dissolved in dilute hydrochloric acid. After the addition of sodium sulphate, lead sulphate and the remaining lead dioxide was filtered off.

The perchlorate of the dyestuff was precipitated with sodium perchlorate and was recrystallized twice from $3 \%$ and $0.1 \%$ acetic acid, respectively. The perchlorate was obtained as shining green needles with a violet lustre when viewed from certain angles. (Found: C 57.9; $\mathrm{H}$ 5.42; $\mathrm{N} \mathrm{6.29;} \mathrm{Cl} \mathrm{8.18;} \mathrm{S}$ 7.5. Calc. for $\mathrm{C}_{21} \mathrm{H}_{23} \mathrm{O}_{4} \mathrm{~N}_{2} \mathrm{ClS}$ : C 58.0; $\mathrm{H} \mathrm{5.33}$; $\mathrm{N}$ 6.44; Cl 8.15; $\mathrm{S} 7.37$ ).

Stock solutions of the dye were prepared in the same manner as in Ref. ${ }^{8}$ The chemicals used for the buffers and the apparatus used for the measurements were the same as in Ref. ${ }^{6}$

\section{MEASUREMENTS AND RESULTS}

In acetate buffer, $\mathrm{pH}=4.8$ Thiophene Green produces only one coloured species and more than $99 \%$ of the dye is present as the coloured ion $\mathrm{B}$. In Fig. 1 there can be seen the absorption curves for the green ion B in acetate buffer and for the red-yellow ion $\mathrm{G}$ in $0.2 \mathrm{M}$ hydrochloric acid. The molecular extinction coefficients were calculated from the experimentally obtained absorption curves and eqn. (2) $\left(e_{\mathrm{B}}=C_{\mathrm{M}} \varepsilon_{\mathrm{B}}\right.$ and $\left.e_{\mathrm{G}}=C_{\mathrm{M}} \varepsilon_{\mathrm{G}}\right)$. The following values were obtained: $\lambda_{\mathrm{B} \max }=628 \mathrm{~m} \mu$ and $467 \mathrm{~m} \mu ; \varepsilon_{\mathrm{B} \max }=7.5 \times 10^{4}$ and $2.55 \times 10^{4}$ resp. $\lambda_{\mathrm{G} \max }=505 \mathrm{~m} \mu ; \varepsilon_{\mathrm{G} \max }=2.80 \times 10^{4}$.

An absorption curve of $\mathrm{TG}$ in $98 \%$ acetic acid and $2 \%$ acetone gave $\lambda_{\mathrm{B} \max }=631 \mathrm{~m} \mu$ and $471 \mathrm{~m} \mu ; \varepsilon_{\mathrm{B} \max }=8.6 \times 10^{4}$ and $2.8 \times 10^{4}$, respectively.

Determination of $K_{1}$. The dye stock solution was mixed with an equivalent volume of suitable $\mathrm{HCl}+\mathrm{KCl}$-buffers and $e_{\mathrm{o}}$ was determined by extrapolation

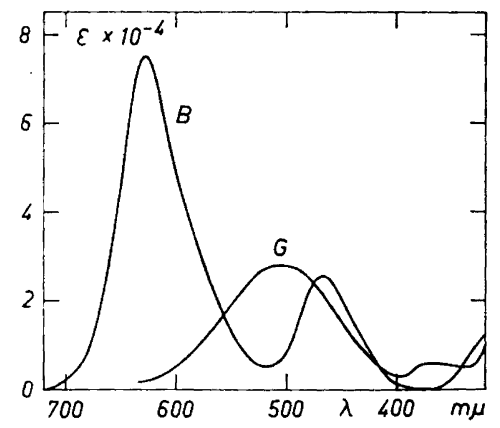

Fig. 1. Thiophene Green. Absorption curves. B is the curve for the green ion $\left[\left(\mathrm{Me}_{2} \mathrm{NC}_{6} \mathrm{H}_{4}\right)_{2} \mathrm{CC}_{4} \mathrm{H}_{3} \mathrm{~S}\right]+$ in acetate, buffer, $G$ is the curve for the yellow-red ion

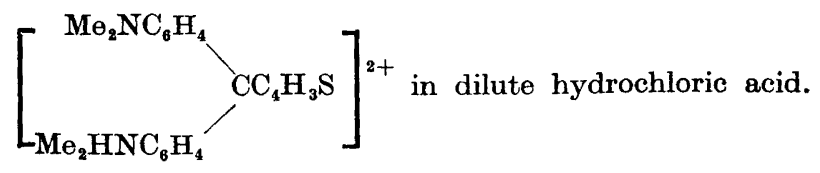

Acta Chem. Scand. 16 (1962) No. 8 
Table 1. Thiophene Green. $e_{0}$ - and $e_{\infty}$-values for the determination of $K_{1}$ and $K_{2}$. $\lambda=630 \mathrm{~m} \mu, C_{\mathrm{M}}=1 \times 10^{-5} \mathrm{M}, d=1 \mathrm{~cm}, e_{\mathrm{B}}=0.720, \mathrm{~T}=20.0^{\circ} \mathrm{C}$.

\begin{tabular}{|c|c|c|c|}
\hline$[\mathrm{H}+] \mathrm{M}$ & $e_{\mathrm{o}}$ & $e_{\infty}$ & $K_{2}$ \\
\hline 0.010 & 0.562 & 0.302 & 3.99 \\
0.020 & 0.464 & 0.192 & 3.97 \\
0.030 & 0.398 & 0.142 & 3.92 \\
0.040 & 0.342 & 0.112 & 3.93 \\
0.050 & 0.304 & 0.092 & 3.99 \\
0.060 & 0.275 & 0.078 & 4.01 \\
0.070 & 0.247 & 0.069 & 3.95 \\
0.080 & 0.228 & 0.0615 & 3.95 \\
\hline \multicolumn{2}{|l}{} \\
Mean value
\end{tabular}

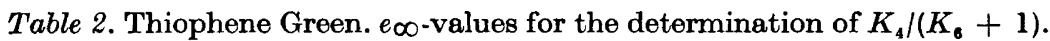
$C_{\mathrm{M}}=1 \times 10^{-5} \mathrm{M}, d=1 \mathrm{~cm}, \lambda=630 \mathrm{~m} \mu, T=20.0^{\circ}$.

\begin{tabular}{|c|c|c|c|}
\hline$[\mathrm{H}+] \times 10^{7} \mathrm{M}$ & $e_{\infty}$ & {$[\mathrm{H}+] \times 10^{7} \mathrm{M}$} & $e_{\infty}$ \\
\hline 1.948 & 0.640 & 0.512 & 0.470 \\
\hline 1.547 & $\begin{array}{l}0.622 \\
0.070\end{array}$ & 0.338 & 0.403 \\
\hline 1.257 & 0.598 & 0.240 & 0.340 \\
\hline 0.954 & 0.570 & 0.182 & 0.290 \\
\hline 0.741 & 0.530 & 0.0911 & 0.174 \\
\hline
\end{tabular}

of the absorbancies to $t=0$. The measurements were carried out at the wavelength $\lambda=630 \mathrm{~m} \mu$. In Fig. $2\left[\mathrm{H}^{+}\right] /\left(e_{\mathrm{B}}-e_{\mathrm{o}}\right)$ is plotted against $\left[\mathrm{H}^{+}\right]$. A straight line is obtained. The slope $l$ and the intercept $y$ on the ordinate-axis of this line and eqn. (4) give $\left(e_{\mathrm{B}}=0.720\right): y=0.0504 \mathrm{M} ; l=1.405 ; \mathrm{K}_{1}=27.9 \pm 0.5 \mathbf{M}^{-1}$.

Determination of $K_{2}$. The dye stock solution was mixed with $\mathrm{HCl}+\mathrm{KCl}-$ buffers and the equilibrium absorbancies, $e_{\infty}$, were measured in $1 \mathrm{~cm}$ absorption cells. $K_{2}$ was calculated from eqn. (5), where $K_{1}=27.9$ is known and $1 / K_{6}\left\langle<1 . e_{\mathrm{B}}=0.720 ; e_{\mathrm{G}}=0.008\right.$ at the used wavelength, $630 \mathrm{~m} \mu$. The results are recorded in Table 1 . From this table the mean value $K_{2}=3.96 \pm 0.10$ is obtained.

Determination of $K_{4} /\left(K_{6}+1\right)$. A dye stock solution was mixed with appropriate phosphate buffers, $\mathrm{pH}=6.7-8.0$, and the equilibrium absorbancies, $e_{\infty}$, where read after 30 h. $C_{\mathrm{M}}=1 \times 10^{-5}, d=1 \mathrm{~cm}, \lambda=630 \mathrm{~m} \mu$. In Fig. 3 $\left[\mathrm{H}^{+}\right] / e_{\infty}$ is plotted against $\left[\mathrm{H}^{+}\right]$. A straight line is obtained, which gives $l=1.367 ; y=0.382 \times 10^{-7} \mathrm{M}$ and from eqn. $(6) K_{4} /\left(K_{6}+1\right)=2.79 \times 10^{-8} \mathrm{M}$ is obtained.

Determination of $K_{3} K_{4}$. The following expression for the equilibrium absorbancy can be derived

$$
e_{\infty}=\frac{e_{\mathrm{B}}+K_{1} \mathrm{~h} e_{\mathrm{G}}}{1+1 / K_{6}+K_{1} \mathrm{~h}+\mathrm{h} / K_{3} K_{6}+K_{4} / K_{6} \mathrm{~h}}
$$

Acta Chem. Scand. 16 (1962) No. 8 


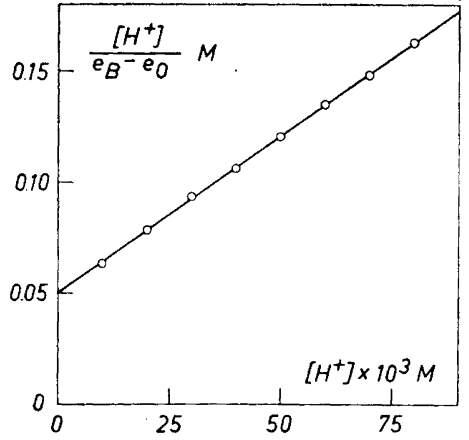

Fig. 2. $[\mathrm{H}+] /\left(e_{\mathrm{B}}-e_{\mathrm{o}}\right)$ plotted against $\left[\mathrm{H}^{+}\right]$ for the determination of $K_{1}$.

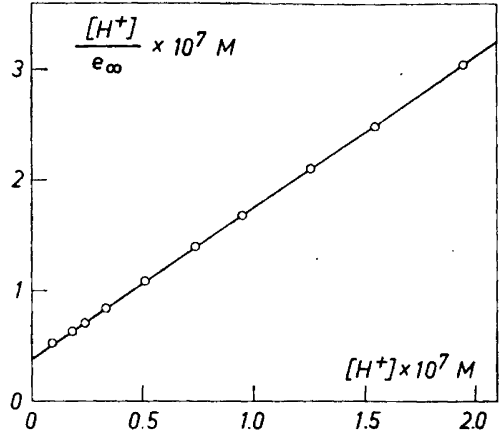

Fig. 3. $[\mathrm{H}+] / e_{\infty}$ plotted against $[\mathrm{H}+]$ for the determination of $K_{4} /\left(K_{6}+1\right)$.

In very weakly acid solutions, $\mathrm{pH}>3.5, K_{1} \mathrm{~h}$ can be neglected in the denominator and $K_{1} \mathrm{~h} e_{\mathrm{G}}$ in the numerator, if the measurements are carried out at a wavelength where $e_{\mathrm{G}} \leq e_{\mathrm{B}}$. After these approximations we can differentiate $e_{\infty}$ in respect of $\left[\mathrm{H}^{+}\right]$and find that $e_{\infty}$ has a maximum when $\left[\mathrm{H}^{+}\right]=\sqrt{K_{3} K_{4}}$. Fig. 4 is obtained by plotting $e_{\infty}$ against $\left[\mathrm{H}^{+}\right]$. From the figure $\mathrm{pH}_{e_{\infty}}$ max $4.79 \pm 0.01$ is obtained, which gives $\sqrt{K_{3} K_{4}}=(1.62 \pm 0.04) \times 10^{-5} \mathrm{M}$. The accuracy of $K_{3} K_{4}$ is not very high, since the curve is rather flat in a large pHrange on both sides of the maximum.

There is, however, another, more accurate method of determining $K_{3} K_{4}$. We can write eqn. (3) as follows, since $h K_{1}<<1$ in the actual pH-range,

$$
\frac{k_{4} \mathrm{~h} K_{3}}{\mathrm{~h}^{2}+\mathrm{h} K_{3}+K_{3} K_{4}}+k_{3}=k-\frac{k_{2} \mathrm{~h}^{2}+k_{6} K_{3} K_{4}}{\mathrm{~h}^{2}+\mathrm{h} K_{3}+K_{3} K_{4}}-\frac{k_{1} \mathrm{~h} K_{1}+k_{5} \mathrm{oh}}{\mathrm{h} K_{1}+1}=k-A
$$

In eqn. (8) $A$ is a correction term which amounts to $1-5 \%$ of $k$ in the $\mathrm{pH}$ range 5.5-4.2. Therefore, it is not necessary to know the constants in the term $A$ at any high degree of accuracy in the following treatment of eqn. (8). If eqn. (8) is differentiated with respect to $\left[\mathrm{H}^{+}\right]$, it is found that $k-A$ has a maximum when $\left[\mathrm{H}^{+}\right]=\sqrt{K_{3} K_{4}}$

$$
(k-A)_{\max }=\frac{k_{4} K_{3}}{K_{3}+2 \sqrt{K_{3} K_{4}}}+k_{3}
$$

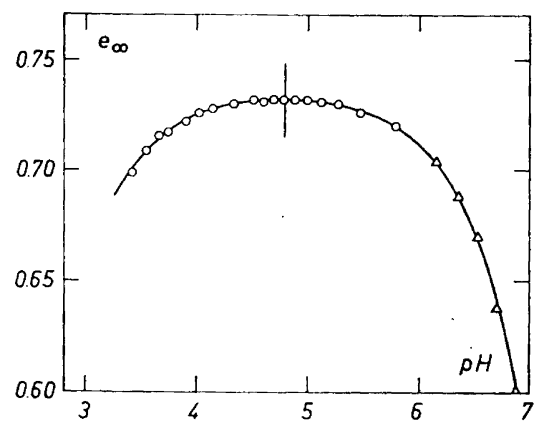

Fig. 4. $e_{\infty}$ as a function of $\mathrm{pH}$ for the determination of $K_{3} K_{4}$.

Acta Chem. Scand. 16 (1962) No. 8 


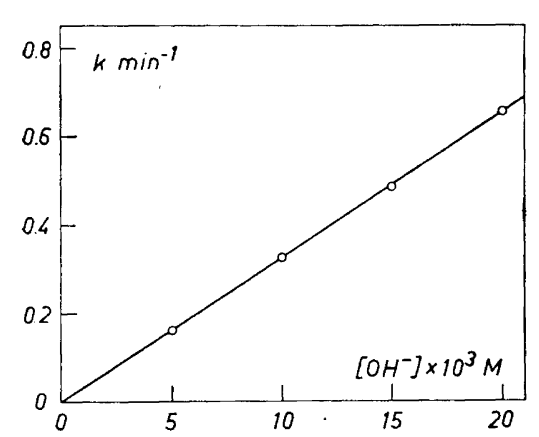

Fig. 5. $k$ plotted against $\left[\mathrm{OH}^{-}\right]$for the determination of $k_{5}$.

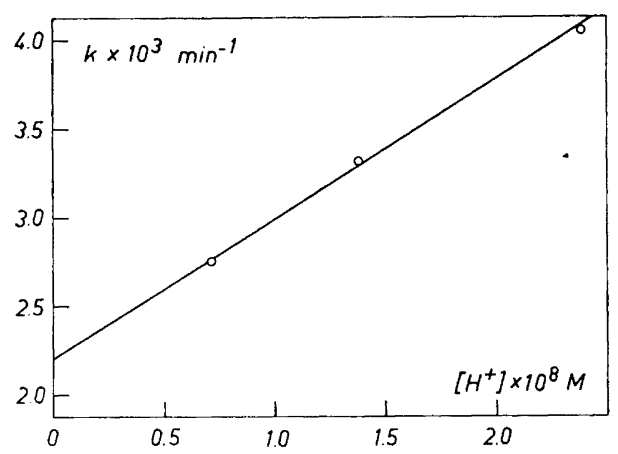

Fig. 6. $k$ plotted against $[\mathrm{H}+]$ for the determination of $k_{3}$.

Through kinetic measurements, which are reported below, $k-A$ was found to have a maximum when $\mathrm{pH}=4.795 \pm 0.005$ giving $\sqrt{K_{3} K_{4}}=(1.60 \pm 0.02)$ $\times 10^{-5} \mathrm{M} ; k_{\max }=0.274 \mathrm{~min}^{-1}$ and $(k-A)_{\max }=0.271 \mathrm{~min}^{-1}$. The value of $\sqrt{K_{3} K_{4}}$ obtained in this way agrees well with the value obtained from the equilibrium measurements.

Determination of $k_{5}$. For alkaline solutions eqn. (3) can be used in the following approximated form

$$
k=k_{3}+k_{5} \mathrm{oh}+k_{6}
$$

The dye stock solution was mixed with $\mathrm{NaOH}+\mathrm{KCl}$-buffers and the fading rate was determined. In Fig. 5 the rate constant of the decolourization, $k$ in eqn. (10), is plotted against $\left[\mathrm{OH}^{-}\right]$. A straight line is obtained which passes almost through the origin. Consequently, $k_{3}+k_{6}\left\langle<k_{5}\right.$ oh in the $\mathrm{pH}$-range used and only $k_{5}$ can be determined from Fig. 5, which gives $\mathbf{k}_{5}=32.7 \pm 0.3 \mathbf{M}^{-1}$ $\min ^{-1}$.

Determination of $k_{3}$ and $K_{4} / K_{6}$. The rate constant $k_{3}$ was determined from kinetic measurements in phosphate buffers, pH 7-8. Eqn. (3) was approximated to

$$
k=k_{4} \mathrm{~h} / K_{4}+k_{3}
$$

since $k_{3} \gg k_{5} \mathrm{oh}+k_{6}$ in this pH-range. In Fig. $6 k$ is plotted as a function of $\left[\mathrm{H}^{+}\right]$. The straight line obtained gives $\mathbf{k}_{3}=\mathbf{0 . 0 0 2 2 1} \pm 0.00003 \mathrm{~min}^{-1}$ and $k_{4} / K_{4}=7.85 \times 10^{4} \mathrm{~min}^{-1} \mathrm{M}^{-1}$. But since $k_{4}=k_{3} K_{6}$, we get $K_{4} / K_{6}=2.82 \times$ $10^{-8} \mathrm{M}$ in excellent agreement with the value of $K_{4} /\left(K_{6}+1\right)=2.79 \times 10^{-8} \mathrm{M}$, since $K_{6} \gg>1$, obtained by equilibrium measurements which have been reported above.

Determination of $K_{3}, K_{4}, K_{6}, k_{4}$, and $k_{6}$. A dye stock solution was partially decolourized by making it $0.02 \mathrm{M}$ with respect to hydrochloric acid. The following reactions then occur in the forward direction $(\rightarrow): \mathrm{B}+\mathrm{H}^{+}+\mathrm{H}_{2} \mathrm{O} \rightleftharpoons \mathrm{G}+$ $\mathrm{H}_{2} \mathrm{O} \rightleftharpoons \mathrm{S}^{\prime \prime}$ and $\mathrm{B}+\mathrm{H}^{+}+\mathrm{H}_{2} \mathrm{O} \rightleftharpoons \mathrm{S}^{\prime}+\mathrm{H}^{+} \rightleftharpoons \mathrm{S}^{\prime \prime}$. This partially decolourized dye solution was then mixed with acetate buffers and the colour was more or 


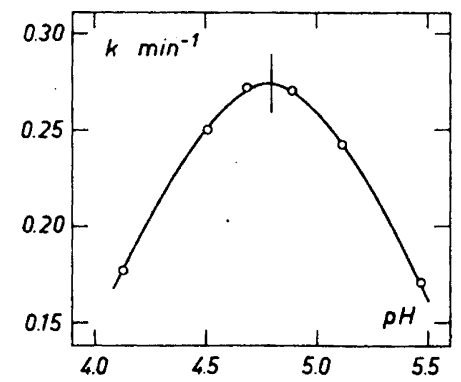

Fig. 7. The total rate constant $k$ as a function of $\mathrm{pH}$. The points represented by the symbols, $O$, are obtained experimentally. The curve is calculated from the non-approximated eqn. (3).

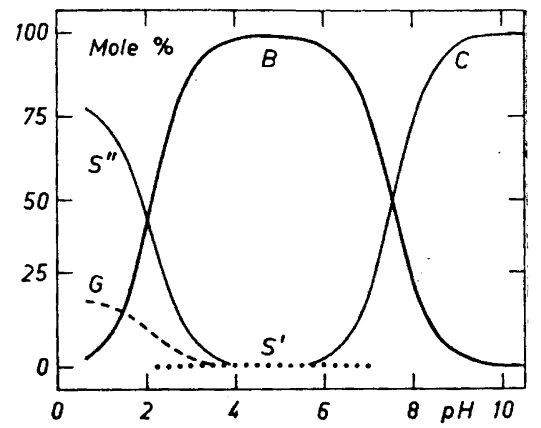

Fig. 8. The distribution of Thiophene Green between the different species as a function of $\mathrm{pH}$.

less restored owing to the reactions above in the reverse direction. The rate constant for the restoring of the colour was determined at different $\mathrm{pH}$-values.

In Fig. $7 k$ is plotted as a function of pH. Eqn. (9) can be written in the following form

$$
(k-A)_{\max }=\left(\frac{K_{6}}{K_{4}} \cdot \frac{K_{3} K_{4}}{K_{3}+2 \sqrt{K_{3} K_{4}}}+1\right) k_{3}
$$

since $k_{4}=k_{3} K_{6}$. From Fig. $7 k_{\max }=0.274 \mathrm{~min}^{-1}$ is obtained and $(k-A)_{\max }$ $=0.271 \mathrm{~min}^{-1}$ using approximate values of the constants in the correction term $A$. In eqn. (12) $K_{3} K_{4}=2.57 \times 10^{-10} \mathrm{M}^{2}$ is known (cf. p. 1843) and so is $k_{3}$ and $K_{6} / K_{4}$. Consequently, $K_{3}$ can be calculated. The following results were obtained $K_{3}=(4.38 \pm 008) \times 10^{-5} M, K_{4}=(5.87 \pm 0.10) \times 10^{-6} M, K_{6}=209 \pm 4$, $\mathbf{k}_{4}=0.462 \pm 0.010 \mathrm{~min}^{-1}$. The rate constant $\mathrm{k}_{6}=(1.44 \pm 0.06) \times 10^{-5} \mathrm{~min}^{-1}$ is obtained from $k_{6}=k_{5} K_{\mathrm{W}} K_{6} / K_{4},\left(K_{\mathrm{W}}=1.24 \times 10^{-14} \mathrm{M}^{2}\right)$.

The distribution of Thiophene Green between the different species at equilibrium is calculated for different $\mathrm{pH}$-values and shown as a function of pH in Fig. 8.

Table 3. Thiophene Green. The total rate constant, $k$, from kinetic measurements in $\mathrm{HCl}+$ $\mathrm{KCl}$-buffers and the rate constant $k_{1}$ calculated from eqn. (13). $C_{\mathrm{M}}=1 \times 10^{-5} \mathrm{M}$, $d=1 \mathrm{~cm}, \lambda=630$ and $500 \mathrm{~m} \mu, T=20.0^{\circ} \mathrm{C}$.

\begin{tabular}{|c|c|c||c|c|c|}
\hline$[\mathrm{H}+] \mathrm{M}$ & $k \mathrm{~min}^{-1}$ & $k_{1} \mathrm{~min}^{-1}$ & {$[\mathrm{H}+] \mathrm{M}$} & $k \min ^{-1}$ & $k_{1} \min ^{-1}$ \\
\hline 0.010 & 0.0307 & 0.0569 & 0.100 & 0.0712 & 0.0712 \\
0.020 & 0.0385 & 0.0590 & 0.120 & 0.0753 & 0.0730 \\
0.040 & 0.0495 & 0.0615 & 0.160 & 0.0845 & 0.0775 \\
0.060 & 0.0578 & 0.0645 & 0.200 & 0.0928 & 0.0838 \\
0.080 & 0.0647 & 0.0675 & 0.250 & 0.1036 & 0.0914 \\
\hline
\end{tabular}


Fig. 9. The rate constant $k_{1}$ calculated from 0.06 eqn. (13) plotted against $[\mathbf{H}+]$.

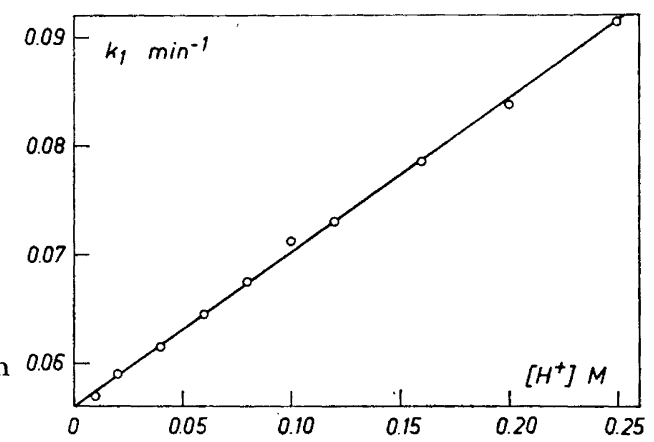

Determination of $k_{1}$ and $k_{2}$. These rate constants were determined by kinetic measurements of the decolourization, which is caused by the reactions $\mathrm{G}+$ $\mathrm{H}_{2} \mathrm{O} \rightleftharpoons \mathrm{S}^{\prime \prime}$ and $\mathrm{B}+\mathrm{H}_{2} \mathrm{O} \rightleftharpoons \mathrm{S}^{\prime}$, when a dye stock solution is mixed with $\mathrm{HCl}+\mathrm{KCl}$-buffers. Eqn. (3) can be approximated and since $k_{2}=k_{1} / K_{2}$, it is transformed to

$$
k_{1}=\frac{k-k_{4} K_{3} / \mathrm{h}-k_{3} /\left(1+K_{1} \mathrm{~h}\right)}{1 / K_{2}+K_{1} \mathrm{~h} /\left(1+K_{1} \mathrm{~h}\right)}
$$

and $k_{1}$ can be calculated from eqn. (13) $-K_{1}, K_{2}, k_{3}$, and $k_{4}$ are known. Table 3 contains $k$-values experimentally found and values of $k_{1}$ calculated from eqn. (13). As can be seen from Table $3, k_{1}$ is not constant but increases with $\left[\mathrm{H}^{+}\right]$. In Fig. 9 the values of $k_{1}$ are plotted against $\left[\mathrm{H}^{+}\right]$. A straight line is obtained and an extrapolation to $\left[\mathrm{H}^{+}\right]=0$ gives $\mathrm{k}_{1}=0.056 \pm 0.0005 \mathrm{~min}^{-1}$; $\mathbf{k}_{2}=0.0141 \pm 0.0004 \mathrm{~min}^{-1}$ since $k_{2}=k_{1} / K_{2}$.

\section{DISCUSSION}

If the corresponding figures in Table 4 are compared, it is found that the reactions $\mathrm{B}+\mathrm{H}_{2} \mathrm{O} \stackrel{k_{3}}{\longrightarrow} \mathrm{S}^{\prime}$ and $\mathrm{G}+\mathrm{H}_{2} \mathrm{O} \stackrel{k_{1}}{\longrightarrow} \mathrm{S}^{\prime \prime}$ are notably more slow in Thiophene Green than in Malachite Green. At the same time the values of the

Table 4. Comparison between corresponding constants of Malachite Green, $o \cdot h y d r o x y ~ M G$, $o$-methoxy MG, and Thiophene Green.

\begin{tabular}{|l|l|l|l|l|l|l|l|l|l|}
\hline & $1 / K_{1}$ & $\begin{array}{c}K_{3} \times \\
10^{5}\end{array}$ & $\begin{array}{c}K_{4} \times \\
10^{8}\end{array}$ & $K_{2}$ & $1 / K_{6}$ & $\begin{array}{c}k_{1} \\
\mathrm{~min}^{-1}\end{array}$ & $\begin{array}{c}k_{2} \\
\mathrm{~min}^{-1}\end{array}$ & $\begin{array}{c}k_{3} \\
\mathrm{~min}^{-1}\end{array}$ & $\begin{array}{c}k_{4} \\
\mathrm{~min}^{-1}\end{array}$ \\
\hline $\begin{array}{l}\text { Malachite Green } \\
\text { o-Hydroxy MG }\end{array}$ & 0.036 & 2.7 & 5.8 & 22 & 0.0147 & 0.168 & 0.0078 & 0.00647 & 0.44 \\
$\begin{array}{l}\text { o-Methoxy MG } \\
\text { Thiophene } \\
\text { Green }\end{array}$ & 0.033 & 3.30 & 4.2 & 3.93 & 0.0038 & 0.045 & 0.0114 & 0.00129 & 0.34 \\
\hline
\end{tabular}

Acta Chem. Scand. 16 (1962) No. 8 
hydration constants $K_{2}$ and $1 / K_{6}$ are lowered - that is, the equilibria are more displaced towards the coloured species in Thiophene Green than in Malachite Green. This depends on the thiophene sulphur, which increases the electron density on the central methane carbon and makes the addition of a polarized water molecule more difficult.

The exchange of a phenyl-group in $\mathrm{MG}$ for a thienyl-group has about the same effect as the substitution of an ortho-hydrogen in the phenyl-group for a hydroxy- or methoxy-group. See Table 4.

Thiophene Green and the hydroxy- and methoxy-derivatives of Malachite Green are similar in another respect too. Previous investigations show that the rate constant $k_{1}$ of $p$-hydroxy, $p$-methoxy (Ref. ${ }^{4}$ ), o-methoxy (Ref. ${ }^{7}$ ), and $o$-hydroxy Malachite Green ${ }^{8}$ increases somewhat with $\left[\mathrm{H}^{+}\right]$, when $k_{1}$ is calculated from the reaction scheme on $\mathrm{p} .1838$. The value of $k_{1}$ of the para-derivatives increases with about $11 \%$ in the range $\left[\mathrm{H}^{+}\right]=30-100 \mathrm{mM}$, whereas the corresponding increase of the ortho-derivatives is about $6 \%$ in the range $\left[\mathrm{H}^{+}\right]=10-100 \mathrm{mM}$. In Thiophene Green $k_{1}$ increases with $60 \%$ in the range $\left[\mathrm{H}^{+}\right]=10-250 \mathrm{mM}$. This effect is not noticeable in the other investigated dyes.

The fact that $k_{1}$ increases linearly with $\left[\mathrm{H}^{+}\right]$in some dyes makes it reasonable to believe that the reaction scheme, which has been used, does not cover all the reactions which influence the results of the measurements.

In strongly acid solutions the dye can probably bond another proton according to the following scheme, which only shows the reactions in strongly acid solutions.

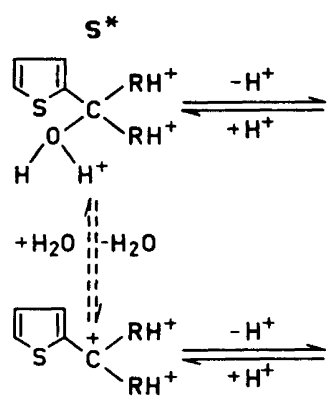

$\mathbf{G}^{0}$

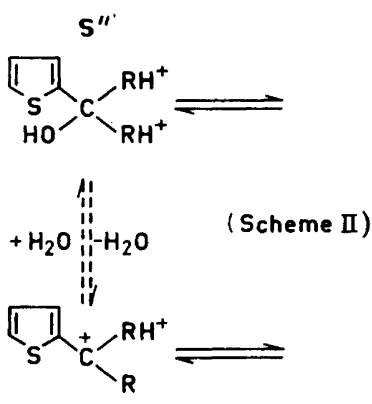

G

The following constants are defined

$$
\begin{gathered}
K_{\mathrm{o}}=\frac{[\mathrm{G}]\left[\mathrm{H}^{+}\right]}{\left[\mathrm{G}^{\circ}\right]} ; K_{\mathrm{o}}^{\prime}=\frac{\left[\mathrm{S}^{\prime \prime}\right]\left[\mathrm{H}^{+}\right]}{\left[\mathrm{S}^{*}\right]} ; K=\frac{\left[\mathrm{S}^{*}\right]_{\infty}}{\left[\mathrm{G}^{\circ}\right]_{\infty}} \\
k_{1}^{\prime}=\text { rate constant for the reaction } \mathrm{G}^{\circ}+\mathrm{H}_{2} \mathrm{O} \rightarrow \mathrm{S}^{*} \\
k_{2}^{\prime}="\|"\| \mathrm{S}^{*} \rightarrow \mathrm{G}^{\circ}+\mathrm{H}_{2} \mathrm{O}
\end{gathered}
$$

The fact that the determination of $K_{1}$ and $K_{2}$ is not obstructed by the presence of the species $G^{\circ}$ and $S^{*}$, indicates that $\left[G^{\circ}\right]_{0}<<[B]_{0}+[G]_{0}$ and $\left[\mathrm{S}^{*}\right]_{\infty}<<[\mathrm{B}]_{\infty}+[\mathrm{G}]_{\infty}+\left[\mathrm{S}^{\prime \prime}\right]_{\infty}$ in the $\mathrm{pH}$-range $1-2$, where $K_{1}$ and $K_{2}$ 
are determined. However, the kinetics can be influenced by the presence of even very low concentrations of $G^{\circ}$ and $S^{*}$, if $k_{1}^{\prime}$ and $k_{2}^{\prime}$ are large compared with $k_{1}$ and $k_{2}$.

The following equations for the kinetics in solutions with $\mathrm{pH}<7$ can be derived, if the reaction scheme on p. 1846 is assumed to be valid

$$
k=\frac{\mathrm{h}^{2} k_{2}^{\prime}+\mathrm{h} k_{2} K_{\mathrm{o}}^{\prime}+k_{4} K_{\mathrm{o}}^{\prime} K_{3}}{\mathrm{~h}^{2}+\mathrm{h} K_{\mathrm{o}}^{\prime}+K_{\mathrm{o}}^{\prime} K_{3}}+\frac{\mathrm{h}^{2} k_{1}^{\prime}+\mathrm{h} k_{1} K_{\mathrm{o}}+k_{3} K_{\mathrm{o}} K_{1}}{\mathrm{~h}^{2}+\mathrm{h} K_{\mathrm{o}}+K_{\mathrm{o}} / K_{1}}
$$

In the pH-range which has been used in Fig. $9, \mathrm{pH}=0.6-2$, it holds that $\mathrm{h} \gg K_{3}$ and $K_{\mathrm{o}}^{\prime} \gg \mathrm{h}$, and eqn. (14) can, therefore, be approximated and at the same time rewritten as

$$
\begin{gathered}
k-k_{4} K_{3} / \mathrm{h}-k_{3} /\left(1+K_{1} \mathrm{~h}\right)=\mathrm{h} k_{2}^{\prime} / K_{\mathrm{o}}^{\prime}+k_{2}+\frac{\mathrm{h} k_{1}^{\prime} / K_{\mathrm{o}}+k_{1}}{1+1 / K_{1} \mathrm{~h}} \\
=\frac{\mathrm{h} k_{1}^{\prime} / K_{\mathrm{o}}+k_{1}}{K_{2}}+\frac{\mathrm{h} k_{1}^{\prime} / K_{\mathrm{o}}+k_{1}}{1+1 / K_{1} \mathrm{~h}}
\end{gathered}
$$

since $k_{1}^{\prime}=K k_{2}^{\prime}, k_{1}=K_{2} k_{2}$, and $K_{\mathrm{o}}^{\prime} K=K_{\mathrm{o}} K_{2}$. If we write $\mathrm{h} k_{1}^{\prime} / K_{\mathrm{o}}+k_{1}=k_{1}^{\circ}$ we finally get

$$
k_{1}^{\mathrm{o}}=\frac{k-k_{4} K_{3} / \mathrm{h}-k_{3} /\left(1+K_{1} \mathrm{~h}\right)}{1 / K_{2}+K_{1} \mathrm{~h} /\left(1+K_{1} \mathrm{~h}\right)}
$$

The right member of eqn. (17) is identical with the right member of eqn. (13) and $k_{1}^{\circ}$ in eqn. (17) corresponds to $k_{1}$ in eqn. (13). If $k_{1}^{\circ}$ is plotted against [ $\left.\mathrm{H}^{+}\right]$, a straight line should be obtained. Fig. 9 gives such a line with the intercept on the ordinate-axis $=k_{1}$ and the slope $=k_{1}^{\prime} / K_{\mathrm{o}}=0.142 \mathrm{~min}^{-1} \mathrm{M}^{-1}$.

Thus, the kinetic measurements strongly support the expanded reaction scheme. The individual values of the constants $K_{\mathrm{o}}, K, K_{\mathrm{o}}^{\prime}, k_{1}^{\prime}$, and $k_{2}^{\prime}$ cannot, however, be determined.

An attempt was made to determine the absorption curve of $G^{\circ}$ but the result was somewhat confusing. The absorption curves of Thiophene Green in various, strongly acidic solutions were recorded in the range $\lambda=320-600 \mathrm{~m} \mu$. A dye solution, which is made $5 \mathrm{M}, 2.5 \mathrm{M}$, and $1 \mathrm{M}$ with respect to $\mathrm{HCl}$, contains at equilibrium about $90 \%, 50 \%$, and $30 \%$, respectively, of the dye in the form of coloured species. The dye is not quite resistent to conc. HCl. An absorption curve obtained with the dye dissolved in $4.5 \mathrm{M} \mathrm{H}_{2} \mathrm{SO}_{4}$ was found to agree with Curve G (Fig. 1) within such narrow limits that only one of the curves has been drawn in Fig. 1. Curve $G$ is calculated from eqn. (2) using the $e_{\infty}$-values obtained from a solution with $\left[\mathrm{H}^{+}\right]=0.2 \mathrm{M}$.

There are two possible explanations of the agreement between Curve G (Fig. 1) and the curve obtained in $4.5 \mathrm{M} \mathrm{H}_{2} \mathrm{SO}_{4}$. First: The species $\mathrm{G}^{\circ}$ and $\mathrm{G}$ may have similar absorption curves in the used wavelength range. If this is true, the equilibrium $\mathrm{G}^{\circ}+\mathrm{H}_{2} \mathrm{O} \rightleftharpoons \mathrm{S}^{*}$ is strongly displaced towards the coloured $G^{\circ}$. Second: The absorption curves of $G^{\circ}$ and $G$ are not similar. If this is true, the ion $G^{\circ}$ does not reach measurable concentrations even in very strongly

Acta Chem. Scand. 16 (1962) No. 8 
acidic solutions. The marked increase of the colour of the dye, when the concentration of acid is raised, must then be explained as a very strong medium effect on the equilibrium $\mathrm{G}+\mathrm{H}_{2} \mathrm{O} \rightleftharpoons \mathrm{S}^{\prime \prime}$. We have found from other measurements of similar dyes that the equilibria "Coloured" $\rightleftharpoons$ "Colourless" are displaced towards the coloured species, if the dielectric constant of the solvent is decreased by the addition of organic substances such as ethanol, acetone and acetic acid, to an aqueous solution of the dye.

The reason for Thiophene Green, and probably $p$ - and $o$-hydroxy and -methoxy Malachite Green too, reacting according to a more complicated scheme than that of $M G$ and the rest of the investigated derivatives of $M G$, is the following: The thienyl-group as well as the hydroxy- and methoxy-substituted phenyl-group has a stronger electron donor character than the non-substituted phenyl-group. This is the reason why the reactions $\mathrm{S}^{\prime \prime}+\mathrm{H}^{+} \rightleftharpoons \mathrm{S}^{*} \rightleftharpoons \mathrm{G}^{\circ}+\mathrm{H}_{2} \mathrm{O}$ and $\mathrm{G}+\mathrm{H}^{+} \rightleftharpoons \mathrm{G}^{\circ}$ are so much facilitated that they manifest themselves in the kinetic measurements of Thiophene Green and the above-mentioned hydroxy-and methoxy-derivatives of MG. In Malachite Green and derivatives of MG with weakly electron-donating substituents these reactions may be possible, although they do not appreciably influence the kinetic measurements at $\mathrm{pH} \approx 1$.

Acknowledgements. The authors are indebted to the Analytical Department of the Chemical Institute, and its head prof. K.-J. Karrman, for the micro elementary analyses, and to prof. S. Fronæus, prof. I. Leden and Dr. J. Sandström for stimulating discussions and comments.

\section{REFERENCES}

1. Levi, L. Ber. 20 (1887) 513.

2. Mason, D. C. and Nord, F. F. J. Org. Chem. 16 (1951) 722.

3. Mason, D. C. and Nord, F. F. J. Org. Chem. 17 (1952) 778.

4. Cigén, R. Protolysengleichgewichte und Reaktionsgeschwindigkeiten einiger basischer Triphenylmethanfarbstoffe (Diss.), University, Lund 1956.

5. Cigén, R. Acta Chem. Scand. 14 (1960) 979.

6. Cigén, R. Acta Chem. Scand. 15 (1961) 1892.

7. Cigén, R. Acta Chem. Scand. 15 (1961) 1905.

8. Cigén, R. Acta Chem. Scand. 16 (1962) 192. 